\title{
56. Monosaccharide Pattern of Egg Jellies in Three Species of Hynobius*)
}

\author{
By Mamoru Kusa and Eiji OzU \\ Department of Biology, Yamagata University, Yamagata \\ (Comm. by Yô K. OKADA, M.J.A., April 12, 1961)
}

Amphibian eggs, in general, are characterized by a thick jelly envelope, in analogy with sea urchin eggs, which are coated by a jelly layer. These egg jellies in the sea urchins have received increasing attention in relation to the problems of fertilization; as for their chemistry, an important finding has been presented by Vasseur and Immers (1949), that the carbohydrate moiety in the studied genera or species has specific sugar components. More recently, with the egg jellies from some amphibians, a similar configuration of monosaccharide specificity has also been established by Minganti (1955).

In view of this growing interest in the problem, an attempt has been made to gain preliminary information on the monosaccharide pattern of the egg jellies in three species of the genus Hynobius (urodelan amphibian): viz. Hynobius retardatus, $H$. nigrescens, and H. tokyoensis. The results obtained will be presented below.

Before proceeding further, we wish to express our sincere gratitude to Dr. A. Sakai, Institute of Low Temperature Science, Hokkaido University, for suggestions and criticisms in connection with the chromatography, and to Professor K. I. Hanaoka, Gunma University for interest and aid. Acknowledgment is also due to Professor Y. Watanabe of the Tôhô University for his discussions.

Methods. Separation of the monosaccharides was done by paper partition chromatography with egg jelly taken from natural spawnings. The jelly was dissolved by treatment with $1 \mathrm{~N} \mathrm{NaOH}$ and then neutralized by addition of $\mathrm{HCl}$. After two days' dialysis against distilled water, the dissolved jelly was condensed, and $1 \mathrm{~N} \mathrm{H}_{2} \mathrm{SO}_{4}$ was added to it. The sealed tube containing the mixture was heated in a boiling water bath for 6 hours; the hydrolysate thus obtained was neutralized with $\mathrm{Ba}(\mathrm{OH})_{2}$. With the precipitates centrifuged off, the supernatant was again condensed into a syrup under reduced pressure at room temperature. The pyridine extract of the hydrolysate was subjected to chromatographic analysis. Ascending chromatograms were run seven times consecutively using Toyo No. 50 paper in $n$-butanol-acetic

* Read before the 31st Annual Meeting of the Zoological Society of Japan held at Nishinomiya, on Oct. 16th, 1960. This study was aided in part by the Scientific Research Fund from the Ministry of Education. 
acid-water (4:1:2); the detection of sugar spots was made either with aniline hydrogen phthalate or benzidine reagents, which produced similar results.

For quantitative analysis of monosaccharides separated on the paper chromatograms, the area containing the sugar, which was identified beforehand by developing a parallel strip, was cut out and extracted with $15 \mathrm{ml}$ of distilled water; after adding anthrone reagent to the elute, colorimetric analysis was made using a Beckman spectrophotometer at $620 \mathrm{~m} \mu$.

Results and discussion. Five spots were found in the chromatogram of the hydrolysate of the egg jelly from $H$. retardatus; parallel runs of the standard sugars indicate that the three major spots correspond to fucose, mannose, and galactose, respectively (Fig. 1). However, the remaining two, one located between fucose and mannose and the other above fucose, have not yet been identified. Below galactose are seen some small spots, which may be due to oligosaccharides, produced probably by the incomplete hydrolysis of the jelly substances. Tests with the jelly from the other urodelan species, $H$. nigrescens and $H$. tokyoensis, revealed the presence of a similar pattern of monosaccharides (Fig. 2).

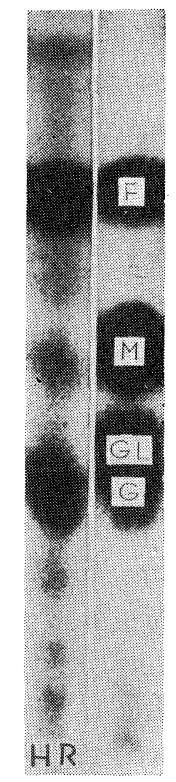

Fig. 1. Paper chromatograms of hydrolysates of the egg jelly from Hynobius retardatus, and of reference standards. F, fucose; M, mannose; Gl, glucose; and $\mathrm{G}$, galactose

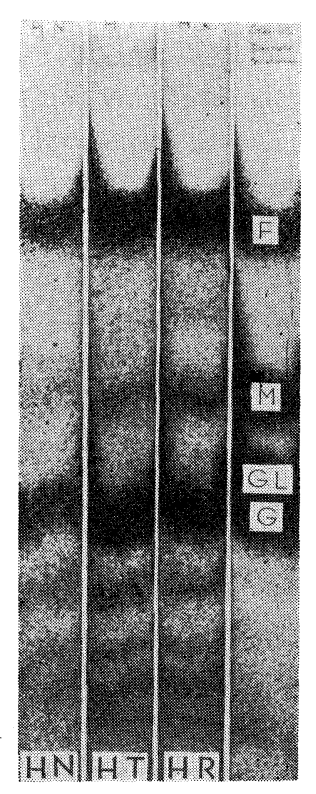

Fig. 2. Comparison of monosaccharide patterns of the egg jelly from three species of Hynobius. HN, $H$. nigrescens; HR, H. retardatus; and HT, H. tokyoensis. Fourth strip shows spots of markers; symbols as in Fig. 1 
The quantitative determination of these monosaccharides made with the elute of the chromatograms from the egg jelly gave the results presented in the following table. Inspection of the table reveals that, in the three species examined, the major sugars are contained in the order of fucose $>$ galactose $>$ mannose, but in different proportions in different species.

Relative contents, denoted by absorbance readings, of monosaccharide residues identified in egg jelly from three species of Hynobius.

Comparisons among species can only be made with values in parentheses, mannose being taken as a standard.

\begin{tabular}{c|c|c|c}
\hline \multicolumn{1}{c|}{ Species } & Galactose & Mannose & Fucose \\
\hline H. retardatus & $0.165(235)$ & $0.070(100)$ & $0.290(415)$ \\
\hline H. nigrescens & $0.085(131)$ & $0.065(100)$ & $0.120(184)$ \\
\hline H. tokyoensis & $0.105(121)$ & $0.087(100)$ & $0.196(225)$ \\
\hline
\end{tabular}

Consequently, there seems to be little difference among the three species of Hynobius with respect to their monosaccharide patterns. Minganti (1955) has reported that the amphibian egg jelly differs in monosaccharide residues according to species: namely, galactose and fucose in Rana esculenta, galactose, mannose, and fucose in Bufo vulgaris, glucose, mannose, and fucose (?) in Discoglossus pictus, mannose and fucose in the axolotl. Therefore our findings differ essentially from those of Minganti (1955) in showing little species specificity in the monosaccharide pattern, and suggesting that the genus Hynobius is characterized by a common pattern, similar to some European sea urchins in which genus specificity in the egg jelly has been postulated (Vasseur and Immers, 1949). However, in view of the somewhat inconsistent data now available from other sea urchins (Tyler, 1949; Nakano and Ohashi, 1954; Monroy, Tosi, Giardina, and Maggio, 1954), Vasseur's concept has been questioned (Rothschild, 1956). On the basis of these considerations, it would be premature to explain our findings by assuming genus specificity in the monosaccharide pattern of the egg jelly in Hynobius, before further comparison within the genus is available.

Summary. A comparative study was made of the carbohydrate moiety of the egg jelly in three species of Hynobius, $H$. retardatus, $H$. nigrescens, and $H$. tokyoensis, by means of paper partition chromatography. These three species present no species-specific monosaccharide pattern, having a similar, though not wholly identical, pattern which contains mainly fucose, mannose, and galactose. At present, however, it remains uncertain whether this profound similarity be- 
tween the monosaccharide patterns can be relied upon as a biochemical manifestation of genus specificity in the egg jelly of Hynobius.

\section{References}

Minganti, A. (1955): Chemical investigations on amphibian egg jellies, Exptl. Cell Res., suppl., 3, 248-251.

Monroy, A., Tosi, L., Giardina, G., and Maggio, R. (1954): Further investigations on the interaction between sperm and jelly-coat in the fertilization of sea urchin egg, Biol. Bull., 106, 169-177.

Nakano, E., and Ohashi, S. (1954): On the carbohydrate component of the jelly coat and related substances of eggs from Japanese sea urchins, Embryologia, 2, 81-86.

Rothschild, Lord (1956): Fertilization, Methuen, London.

Tyler, A. (1949) : Properties of fertilizin and related substances of eggs and sperm of marine animals, Amer. Nat., 83, 195-219.

Vasseur, E., and Immers, J. (1949): Genus specificity of the carbohydrate in the sea urchin egg jelly coat as revealed by paper chromatography, Ark. Kemi, 1, 39-41. 